\title{
Looking for the Silver Lining: Benefit Finding After Hurricanes Katrina and Rita in Middle-Aged, Older, and Oldest-Old Adults
}

\author{
Katie E. Stanko \\ Louisiana State University at Baton Rouge \\ Katie E. Cherry \\ Louisiana State University at Baton Rouge \\ Kyle S. Ryker \\ Louisiana State University at Baton Rouge \\ Farra Mughal \\ Louisiana State University at Baton Rouge \\ Follow this and additional works at: https://scholarsarchive.byu.edu/facpub \\ UrearPoAtarksther Social and Behavioral Sciences Commons \\ Brigham Young University - Provo, loren_marks@byu.edu

\section{Original Publication Citation}

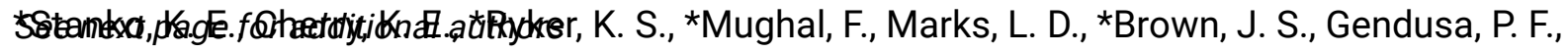 \\ *Sullivan, M. C., Bruner, J., Welsh, D. A., Su, L. J., \& Jazwinski, S. M. (2015). Looking for the silver \\ lining: Benefit finding after Hurricanes Katrina and Rita in middle-aged, older, and oldest-old \\ adults. Current Psychology, 34, 564-575.
}

\section{BYU ScholarsArchive Citation}

Stanko, Katie E.; Cherry, Katie E.; Ryker, Kyle S.; Mughal, Farra; Marks, Loren D.; Brown, Jennifer Silva; Gendusa, Patricia F.; Sullivan, Marisa C.; Bruner, John; Welsh, David A.; Su, L. Joseph; and Jazwinski, S. Michael, "Looking for the Silver Lining: Benefit Finding After Hurricanes Katrina and Rita in Middle-Aged, Older, and Oldest-Old Adults" (2015). Faculty Publications. 4865.

https://scholarsarchive.byu.edu/facpub/4865

This Peer-Reviewed Article is brought to you for free and open access by BYU ScholarsArchive. It has been accepted for inclusion in Faculty Publications by an authorized administrator of BYU ScholarsArchive. For more information, please contact ellen_amatangelo@byu.edu. 


\section{Authors}

Katie E. Stanko, Katie E. Cherry, Kyle S. Ryker, Farra Mughal, Loren D. Marks, Jennifer Silva Brown, Patricia

F. Gendusa, Marisa C. Sullivan, John Bruner, David A. Welsh, L. Joseph Su, and S. Michael Jazwinski 


\title{
Looking for the Silver Lining: Benefit Finding After Hurricanes Katrina and Rita in Middle-Aged, Older, and Oldest-Old Adults
}

\author{
Katie E. Stanko ${ }^{1}$ (D) Katie E. Cherry ${ }^{1} \cdot$ Kyle S. Ryker $^{1} \cdot$ Farra Mughal $^{1}$ • \\ Loren D. Marks ${ }^{2}$ - Jennifer Silva Brown ${ }^{1}$ - Patricia F. Gendusa ${ }^{1}$. \\ Marisa C. Sullivan ${ }^{1} \cdot$ John Bruner ${ }^{1}$. David A. Welsh ${ }^{3} \cdot$ L. Joseph $\mathrm{Su}^{3}$. \\ S. Michal Jazwinski ${ }^{4}$ • for the Louisiana Healthy Aging Study
}

Published online: 15 August 2015

(C) Springer Science+Business Media New York 2015

\begin{abstract}
Looking for potentially positive outcomes is one way that people cope with stressful events. In two studies, we

${ }^{\dagger *}$ Meghan B. Allen, BS; Gloria Anderson, BS; Iina E. Antikainen, BS; Arturo M. Arce, MD; Jennifer Arceneaux, RN; Mark A. Batzer, PhD; Emily O. Boudreaux, MA; Lauri Byerley, PhD; Catherine M. Champagne PhD, RD; Katie E. Cherry, PhD; Liliana Cosenza, BS; M. Elaine Cress, PhD-Consultant; Jenny Y. Denver, MS; Andy Deutsch, PhD; Devon A. Dobrosielski, MS; Rebecca Ellis, PhD; Marla J. Erwin, MA; Mark Erwin, MA; Jennifer Fabre, MPT; Elizabeth T. Fontham, PhD; Madlyn Frisard, PhD; Paula Geiselman, PhD; Lindsey Goodwin, BS; Tiffany Hall; Scott W. Herke, PhD; Jennifer Hayden, MS; Kristi Hebert, BS; Fernanda Holton, MA; Hui-Chen Hsu, $\mathrm{PhD}$; S. Michal Jazwinski, PhD; Sangkyu Kim, PhD; Beth G. Kimball, BS; Christina King-Rowley, MS; Kim Landry; Carl Lavie, MD-Consultant; Daniel LaVie, BS; Matthew Leblanc; Christina M. Lefante, MPH; Li Li, MD; Hui-Yi Lin, PhD, MSPH; Kay Lopez, DSN; John D. Mountz, MD PhD; Jennifer Owens, BA; Kim B. Pedersen, PhD; Andrew Pellett, PhD; Eric Ravussin, $\mathrm{PhD}$; Paul Remedios; Yolanda Robertson, NP; Jennifer Rood, PhD; Henry Rothschild, MD, PhD; Ryan A. Russell, BS; Erin Sandifer, BS; Beth Schmidt, MS; Robert Schwartz, MD - Consultant; Donald K. Scott, PhD; Mandy Shipp, RD; Jennifer L. Silva, MA; L. Joseph Su, PhD MPH; Jessica Thomson, PhD; Valerie Toups, LPN; Crystal Traylor, APRN, MSN, WHNP; Cruz Velasco-Gonzalez, PhD; Julia Volaufova, PhD; Celeste Waguespack, BSN, RN; Jerilyn A. Walker, MS; David A. Welsh, MD; Michael A. Welsch, $\mathrm{PhD}$; Robert H. Wood, PhD; Sarah Zehr, PhD; Pili Zhang, PhD. (Louisiana State University, Baton Rouge; Pennington Biomedical Research Center, Baton Rouge; Louisiana State University Health Sciences Center, New Orleans; Tulane University, New Orleans; University of Alabama, Birmingham).
\end{abstract}

Katie E. Stanko

pskatie@1su.edu

1 Department of Psychology, Louisiana State University, Baton Rouge, LA 70803-5501, USA

2 School of Family Life, Brigham Young University, Provo, Utah 84602, USA

3 Louisiana State University Health Science Center, New Orleans, LA 70112, USA

4 Tulane University School of Medicine, New Orleans, LA 70112, USA examined perceived "silver linings" after the 2005 Hurricanes Katrina and Rita among indirectly affected adults. In Study 1, middle-aged (ages 47-64 years), older (ages 65-89 years), and oldest-old (ages 90-95 years) adults in the Louisiana Healthy Aging Study (LHAS) responded to an open-ended question on perceived silver linings in a longitudinal assessment carried out during the immediate impact (1 to 4 months after landfall) and post-disaster recovery phase (6 to 14 months post-storm). Qualitative grounded theory methods were employed to analyze these narrative data. Team-based coding yielded three core themes: (1) learning experience and better preparedness for future disasters, (2) having improved cities (Baton Rouge and New Orleans), and (3) an increase in "Good Samaritan" acts such as strangers helping one another. Responses were similar across age groups, although older adults were the least likely to report positive outcomes. Study 2 was a conceptual replication using a different sample of adults (ages 31 to 82 years) tested at least 5 years after the storms. A learning experience and preparedness core theme replicated Study 1's findings while improved social cohesion amongst family and friends emerged as a new core theme in Study 2. These data indicate that identifying lessons learned and potentially positive outcomes are psychological reactions that may facilitate post-disaster coping and foster resilience for indirectly affected adults in the years after disaster.

Keywords Natural disasters $\cdot$ Hurricane effects $\cdot$ Post-disaster coping $\cdot$ Benefit-finding $\cdot$ Oldest-old $\cdot$ Louisiana Healthy Aging Study

In 2005, Hurricanes Katrina and Rita crashed into the U.S. Gulf Coast, causing catastrophic destruction and extensive damage further inland than had been seen before (Weisler et al. 2006). Numerous studies have addressed Katrina's devastating effects on children, adolescents, and families (Kilmer et al. 2010; 
Weems and Banks 2015), which is critical for disaster planning and policy considerations (Osofsky et al. 2007). Increased attention has also been directed to understanding post-disaster psychological reactions among older adults (Cherry 2009; Cherry et al. 2010a; Henderson et al. 2010; Roberto et al. 2009; Silva Brown et al. 2010). In the decade since Katrina, there have been over 200 natural disasters in the United States alone (EM-DAT 2015), while the number of older adults over the age of 65 has increased to nearly 45 million. An estimated 88.5 million older adults will comprise $20 \%$ of the population by 2050 (United States Census United States Census Bureau 2012). The number of elderly adults who perished in the aftermath of Katrina exceeded the number of deaths of all other age groups combined (Johnson and Galea 2009). Thus, it is crucial to understand how older adults appraise disaster risk and cope with disaster-related stressors in order to inform, promote, and provide better future services to a growing segment of the population who may also have unique age-related needs when confronted with a natural disaster.

There is a sizeable literature on disaster effects in the general population (Neria et al. 2009; Norris et al. 2002), although fewer studies have directly compared middle-aged and older adults. For instance, after Hurricane Hugo struck the east coast in 1989, Thompson et al. (1993) found that middle-aged adults (ages 35-64) were the most affected compared to older adults in their sample, consistent with a burden perspective on post-disaster psychological reactions. That is, middle-aged adults are often the head of households or lead providers for their family. When this role cannot be fulfilled due to unexpected events like a natural disaster, personal recovery is impaired. Cherry et al. (2011) examined post-disaster psychological reactions associated with Hurricanes Katrina and Rita in middle-aged and older adults (47 to 95 years) from the Louisiana Healthy Aging Study (LHAS). Two waves of testing were carried out to examine potential change in responses from the immediate impact period (Wave 1: 1 to 4 months after landfall) and in the post-disaster recovery period (Wave 2: 6 to 14 months after the storms). Middle-aged adults' responses concerning storm-related threat and actual safety during the storms indicated that they were somewhat more afraid and also felt less safe than did their older counterparts in Waves 1 and 2, confirming that the effect is reliable. Middleaged adults were also more likely than their older and oldest counterparts to report moderate to extreme stress associated with their experience of 11 storm-related stressors in Waves 1 and 2, consistent with a burden perspective on post-disaster psychological reactions (see also Solomon et al. 1987; Thompson et al. 1993).

After a life-altering event such as Hurricane Katrina, the metaphorical "road to recovery" can take many routes. Resilience is a common behavioral response across different adverse life events, where survivors "bounce back" from severe stress and adverse circumstances. Indeed, recent psychological research indicates that "most people are surprisingly resilient in the face of trauma" (Gilbert 2007, p. 166). In the adult development and aging literature, resilience has been defined as the maintenance, recovery, or improvement in mental or physical health following challenge (Ryff et al. 2012). Contemporary views on resilience are historically traced to developmental psychology and studies of at-risk youth (Cherry and Galea 2015). In brief, risk and resilience are core concepts that pertain to children's capacity to thrive, despite environmental risks (e.g., poverty, low socioeconomic status, having experienced the death of a parent) and other adverse circumstances (Masten and Narayan 2012; Wright et al. 2013). From a dynamic systems standpoint, Masten (2014) defines resilience as capacity (potential or manifested) of a dynamic system to adapt successfully to disturbances that threaten system function, viability, or development (p. 308) and also positive adaptation or development in the context of significant adversity exposure (p. 308). For an individual to possess the latter definition, protective factors to buffer risk have been identified. Strong attachments and close relationships with others, autonomy (including people's agentic choices), ability to solve problems, social competence, and having a sense of future and perspective amongst other factors have been shown to help promote resiliency when a person is faced with high risk or adversity. The greater depth of these protective factors, the greater capacity of resiliency one will have (Masten 2014).

Building on this theoretical foundation in developmental psychology, we address the phenomenon of benefit finding or looking for silver linings after disaster in the present research to provide new insight into positive coping strategies among indirectly affected middle-aged and older adults. Galea (2012), among others, has made the point that resilience represents the most idealized trajectory after trauma, because peoples' functional capacity and levels of grief and stress return to what they were pre-disaster. This idealized trajectory prompts the vital question, "What can lead people to be resilient after disaster?"

When a disaster strikes, media attention is often drawn to survivors and the devastation of their homes and communities. What, if any, positive effects can arise from such dire circumstances? Although a connection between the terms 'catastrophic disaster' and 'positive outcomes' seems unlikely, some evidence in the social sciences indicates that looking for a silver lining or a bright side of an otherwise desperate situation may provide some relief to survivors coping with great losses (Hatch et al. 2015), thus helping people rise into the trajectory of resilience. For instance, in a meta-analysis by Prati and Pietrantoni (2009), positive reappraisal was highly correlated with posttraumatic growth. Thus, it can be beneficial to a person's overall well-being to be able to look for the "silver lining" in a catastrophe. Consistent with this suggestion, Henderson et al. (2010) found that older adults who were 
displaced by Katrina coped with their situations using strategies that included: religiosity, cultivating positive attitudes of hope and gratitude (for surviving), and reappraising situations in a positive light. In this article, we focus on potential benefits associated with the 2005 hurricanes for indirectly affected adults residing in the greater metropolitan Baton Rouge, LA area (about 80 miles from the devastation in New Orleans). We used a qualitative approach to determine whether age and/ or time since the storm are associated with differences in benefit-finding.

Our earlier work with the LHAS hurricane sample using a quantitative approach has examined cognitive and psychosocial consequences (Cherry et al. 2010a, b, 2011), coping and health (Cherry et al. 2008; Cherry et al. 2009), and healthrelated quality of life and religiosity (Silva Brown et al. 2010). We have also reported qualitative findings concerning religious coping (Tausch et al. 2011; Marks et al. 2009) and volunteer behaviors after the storm based on content analysis of narrative text (Silva, Marks, \& Cherry 2009). This project focused specifically on participants' responses to the "silver lining" question, which we assumed would provide new insight into the processes of positive coping and resilience. Open-ended questions are desirable insofar as they allow an in-depth analysis of how adults of different ages cope with natural disaster.

To summarize, the aims of this study are threefold: 1) determine common themes and ideas in participants' responses to the "silver lining" question, 2) examine potential age differences in adults' reported methods of coping with a natural disaster, and 3) determine whether participants' responses remain the same or change with time.

\section{Study 1}

\section{Participants and Procedure}

Sixty-six individuals enrolled in the LHAS were interviewed during the immediate impact phase (October 2005 to January 2006), as described more fully elsewhere (Cherry et al. 2008, 2009, 2010b). Three groups were compared: middle-aged adults $(n=20 ; M=53.9$ years, $S D=5.9$; age range $=45$ to 64 years), older adults $(n=20 ; M=73.8$ years, $S D=7.2$; age range $=65$ to 89 years $)$, and oldest-old adults $(n=26 ; M=$ 92.0 years, $S D=1.3$; age range $=90$ to 95 years). These individuals had participated in the LHAS up to 6 months before the storms. They were contacted by letter, invited to participate, and followed up with telephone calls. In total, 66 people agreed to participate in the post-storm study (Cherry et al. 2010b). Wave 2 was carried out during the post-disaster recovery period 6 to 14 months after the storms (March 2006 to November, 2006) to examine the temporal stability of responses (Cherry et al. 2011; Silva Brown et al. 2010). Few participants evacuated at the time of the storms, yet nearly all had family and close friends who lived in the more heavily storm damaged areas, and many sheltered displaced family and friends in their homes for days and weeks in the immediate aftermath (Cherry et al. 2008).

Informed consent was obtained for all participants based on the protocol approved by the Louisiana State University Institutional Review Board for the LHAS hurricane assessment (see Cherry et al. 2010b, 2011). To protect anonymity, all participants were assigned a unique three-digit number at Wave 1 testing to denote age group. To be precise, middleaged adults were numbered in the $100 \mathrm{~s}$; older adults in the $200 \mathrm{~s}$, and oldest-old adults in the 300's. For Wave 2 testing, an $\mathrm{R}$ was added to denote retest status in addition to age group: middle aged adults at retest in the 100-Rs; older adults at retest in the 200-Rs, and oldest old adults at retest; 300-Rs. Interviews were conducted in participants' homes or in the laboratory at LSU. The prompt given to all participants was: "They say every cloud has a silver lining and even the most awful events can have positive outcomes. Do you think there are any positive outcomes that can come from Hurricanes Katrina and Rita? If so, what are they?"

\section{Analyses and Coding}

We performed content analyses of the narrative data in a manner consistent with grounded theory methodology (Strauss and Corbin 1998; see also Marks, this issue). In brief, a team of six undergraduate student coders and one graduate student team leader met weekly during the 2014 fall semester to carry out the open coding process, which was based on our earlier qualitative work with the LHAS hurricane assessment study (Tausch et al. 2011). Each student had a coding partner, resulting in three pairs of students who coded the middleaged, older, and oldest-old adults' responses, respectively. Coders were not blind to the participants' ages. Each week, the coding partners met separately to discuss the prevalent ideas and themes covered in the interviews. A weekly team meeting was held with all coders present to compare and contrast codes separately by age group. To ensure that all reported themes for the three age groups were verifiable and clearly supported by the data, the graduate student team leader revisited all interviews within their age group and copied and pasted primary data that had been directly linked with major themes. Thus, the coding approach we implemented was designed to augment the consistency and reliability of the coding scheme (Anfara et al. 2002; see also Marks, this issue). Consequently, each of the major themes reported here had several pages of supporting data drawn from multiple interviews - consistent with Patton's (2002) recommendation of creating a data "audit trail" (p. 93).

For the major themes identified in this article, there were some areas of overlap and similarity across the age groups. 
There were, however, differences in the respective order of importance and salience across age groups. There were also nuances that were captured during the process of team-based qualitative analysis.

\section{Findings}

We begin by presenting the three themes that carried from Wave 1 to Wave 2, as well as across age groups. Collapsed across the age and time of testing variables, these themes were: (1) better preparedness/learning experience, (2) better and improved city (including Baton Rouge and New Orleans), and (3) strangers helping strangers. In terms of age differences, although we asked participants to find the positives in the aftermath of the storms, the older adult group (ages 65-89) specifically listed negative items and stated that any potential positives were not worth it, or that it had been too soon since the storm. Only those in the oldest-old group (ages 90-95) stated that the hurricanes were God's way of punishing and purifying New Orleans. Time of testing differences between Waves 1 and 2 yielded more concern towards corruption and less perceived silver linings in Wave 1 (1-4 months post-landfall) while in Wave 2 (6-14 months later) participants viewed themselves and others returning to religion as a perceived positive. These themes are reported next along with more than 30 illustrative and supportive examples taken directly from the interviews. For the quotes that follow, the numeric code reflects age group and time of testing: middleaged adults (in the $100 \mathrm{~s}$ in Wave 1/100-Rs in Wave 2), older adults (in the $200 \mathrm{~s} / 200-\mathrm{Rs}$ ), and oldest-old adults (in the $300 \mathrm{~s} / 300-\mathrm{Rs})$.

\section{Theme 1 - Better Preparedness and Learning Experience}

Many respondents found Hurricanes Katrina and Rita to be epic tragedies, but realized they could easily happen again. Thus, respondents often expressed their hope for the future in their own preparedness as well as local agencies:

319: Well, the positive outcome would be they can realize how dangerous it is and to better prepare for any future [hurricanes]. Like building better levees and just getting the word out early so that people can prepare better. And, too, they could have transportation ready to take the people out of the danger zones. They didn't do that. They had lots of buses that they did not use. They were flooded and it was too late then to use them (95-year old female).

105-R: Well, like I said earlier, the most important thing is that we learn from this and we [will] be prepared for next time because there will be another next time. And whether it's next year or in 50 years, there will be another storm of this magnitude 1 day.... And I think to have ... from the federal government on down to our own personal household, to have a plan in place and to have an algorithm of what I'm going to do... officials that are in charge of emergency management, things of that nature, be better organized. Especially take [care] of people who can't take care of themselves. Nursing homes, elderly people, people who are indigent who don't have transportation out, and to maybe react a little quicker... I think the most important thing though is that from this awful event that we learn and we be better prepared next time. And I feel confident to say that from every level, we will be more prepared next time (49-year old male).

303-R: Well, first of all, they could prepare for the next one, better prepared. Know what the conditions will be and have remedies for it. Like communication, food supplies, and transportation, mostly under highway regulations. People were [taking] $11 \mathrm{~h}$ [to evacuate the 80 miles] from New Orleans to Baton Rouge on the highway, stalling cars everywhere (92-year old male).

Many respondents identified better preparedness and learning experience as a silver lining like those just presented. A word count for the codes "better prepared" and "learning experience" yielded 55 interviews and 70 specific references to these items across interviews. Whether it be at the individual level, such as preparing important documents and irreplaceable items for evacuation, or at the state and federal level of strengthening levees and ordering evacuation earlier, participants had hoped that everyone had learned from the two hurricanes, and that subsequently there would be an improvement if and when a hurricane was to happen again. We now move to the second and repeatedly identified silver liningbetter and improved cities.

\section{Theme 2 - Better and Improved Cities (Baton Rouge and New Orleans)}

After Hurricane Katrina, Baton Rouge saw an influx of new people as New Orleanians began to relocate after the disaster (Cherry et al. 2010a). Across all three age groups and time elapsed since the respective disasters, the second most prevalent theme was that of "better city." Within this theme, participants reported witnessed improvement in the population of Baton Rouge, and hopeful physical improvements in New Orleans. Many people expressed their concern about the need for stronger infrastructure in New Orleans, with a more resilient levee system and improved evacuation procedures.

As these data were collected 1 to 14 -months postKatrina and Rita, participants remained optimistic that 
time would yield improvements, rebuilding, and regrowth in New Orleans:

209-R: I would love to see New Orleans get redone because it was a city that everybody wanted to go see that was from out of town or that was from out of state and they always had the big Mardi Gras and they had seafood and they had jazz and everything down in New Orleans. It would be a shame if none of that got to be redone again.... [P] eople would go on vacations there because they like the southern hospitality that they got out of there (70-year old female).

219-R: Yeah there is going to be a lot of new buildings. I am talking about business buildings built in New Orleans and subsequently that will bring hopefully new businesses and I think that New Orleans will definitely... I think New Orleans will be a better city than it was before the storm. I believe that (87-year old male).

When many evacuees began to settle in Baton Rouge, however, participants began to see positive changes within their own community:

115-R: Our school came in contact with kids from New Orleans and that was a very good experience for our Baton Rouge kids because these kids are much more metropolitan, much more broad minded. They brought in very intelligent, very intelligent kids. I was so amazed (51-year old female).

In Theme 3, presented next, we address the prosocial theme of brotherly kindness and strangers helping strangers (see also, Marks et al. 2015).

\section{Theme 3 - Strangers Helping Strangers}

Our third emergent theme, strangers helping strangers, unfolded as participants began to reflect on what positives they had seen in their own lives and in those around them. In contrast to media portrayals of looting, violence, and guerilla warfare after Katrina (Barsky et al. 2006; Tierney et al. 2006), several participants perceived the kindness of strangers as a silver lining:

105-R: A month or so after Katrina...I met a group of people, [including] a girl from California of all places, that was here to rescue stray animals. And I was talking to her, and she had given up 2 weeks of her personal time. She was a professional, working person. She flew from California to come here to rescue stray animals (49-year old male).

213-R: I'm sure there are some positive outcomes. I think that the people that worked with evacuees [and] opened their homes to them,...or [people who] have given monetarily, or whatever way... are better people for it. They're compassionate (78-year old female).

314-R: Only thing I can think of is...people being so nice to each other and helping out (93-year old female).

102: But at least I think that people when they really stop and self-reflect, they feel that this is important; that we take care of each other. So I think ...that's a good positive outcome. The volunteer work that I saw people do, that the thousands of people that were volunteering, that was a very good thing (49-year old male).

The observance of unqualified kindness among strangers and other beneficent acts observed in Katrina's immediate aftermath (Cherry et al. 2010a) begs a larger philosophical question. In particular, one must ask whether this well-documented tendency to help others in distress reflects a latent capability or whether empathic responses to storm-ravaged strangers are learned behaviors for those who live in hurricane prone geographic regions? While the origins and motivation for prosocial behavior in the aftermath of a disaster are beyond the scope of this article (see Silva et al. 2009 for related discussion), it does seem that a potential silver lining of Katrina was the creation of multiple contexts in which the expression of helping behaviors, whether latent or learned, could be observed. As we conclude our discussion of Theme 3, we remind the reader that there were areas of both overlap and difference in the participant data across age groups. We turn next to a discussion of the more salient age group and time of testing differences that were revealed in the qualitative analysis.

\section{Age Group Effects}

One salient difference among the three age groups compared and contrasted here was the tendency for some middle-aged participants (ages 47-64) to speculate about new opportunities for Katrina evacuees who were displaced by the storm. A few middle-aged adults reported that the forced displacement could be beneficial for displaced New Orleans natives, offering a fresh start in a new city and maybe a chance for personal growth and possibly a better life. The following quote is illustrative.

103: Well, I think there are a lot [of positive outcomes], but just the very first one that comes to my mind is a lot 
of the people were ... in situations that they had no way to get out of .... Economically, sometimes you are just stuck and you can't go anywhere. And I think that maybe having to leave the city and being placed in areas, whether it's here or anywhere else in the United States, that it might be an opportunity for the beginning of a new life for them where they are not stuck in an area ... I would look at it as to think, well, maybe this is something good. Maybe we can start over here, get some help, you know, look for a job and start over. And I know that a lot of people have done that. They decided that they are not going back to New Orleans. They've already placed their children in schools and decided that, you know, they really didn't want to go back. That they would try to make a life for themselves where ever they were, whether it be here [in Baton Rouge] or in north Louisiana or in Atlanta (56-year old female).

Another middle-aged adult expressed a similar sentiment of having a new life in different city as a silver lining for displaced residents of New Orleans. While watching the evening news on television in the immediate aftermath of the storm, she pondered the plight of displaced evacuees with possibly a happy ending:

116: [W] hen I watched TV and saw the people that, they didn't know where they were going, but they ended up in Utah [laughs]. I remember when I first went to Utah. You know, first of all, looking out of the plane, I wondered, "How in the world did people come to this place?" You know the terrain is so, you know, mountainous, foreboding! I just [thought], how did they [get there]? So anyway, for me, it was a wonderful experience going to Utah. And for some New Orleanians, people who have, you know, there are generations and generations, never to leave, never to want to see any place else. You know, this has got to have been an experience of a lifetime (56-year old female).

While these middle-aged participants' remarks reflect hope for a better life and better times ahead for Katrina evacuees, it should be noted that realizing the benefits of fresh start in a new city may not be easy and may also take time to achieve, as the woman quoted earlier concluded:

103: [A] new life. It can be what you make it. You know, it might be hard for a while, but it can be a good life in somewhere other than where [one lived before the storm]... If I had to leave ... and I knew I could take my family with me ... You know, your heart is where your family is, not where, not a piece of ground. And as long as I was with my family, it wouldn't matter where I was.
Although we asked participants to report any benefits they found in the aftermath of Hurricanes Katrina and Rita, many older adults (ages 65-89) reported that they had lost hope in having positive changes occur:

Interviewer: So you don't see the aftermath of the storm as causing any changes? It's just multiplying almost, the problems that existed before?

206: Right. It will magnify the problems we have and it will cause us to question authority (73-year old male).

Another participant similarly responded:

212: I mean, how can you have a silver lining when you lose everything? (65-year old female).

The following three excerpts seem to reflect the same overriding pessimism.

205-R: I get the feeling they're going to go through it again. They're not going to be better prepared. New Orleans isn't going to be better prepared than they were the first time (77-year old male).

216-R: They are not going to do what needs to be done. They are going to patch it now and later say, "We are not going to have another one like that." We have gone all these years without having a big one .... [We'll] get the money and use it for something else. No, I don't have any hope for them to do that. I would not hold them to it. I don't see that silver lining (74-year old female).

215-R: I was optimistic right after the hurricane that they would end up cleaning up New Orleans, and that it would be a better place after they got all that cleaned up and everything. I've kind of lost hope for that. It doesn't seem like they're going to do what they should be doing (70-year old male).

In the three brief excerpts just mentioned from 65 to 89 year old participants, we see no fewer than eight skeptical and negative expressions regarding New Orleans' future, including "New Orleans isn't going to be better prepared," "No, I don't have any hope," and "I've kind of lost hope for [them improving New Orleans]." Silver linings were less frequently and less richly identified by the older than by the middle-aged group - and the older group was more likely (like 216-R) to implicitly or explicitly convey, "I don't see that silver lining."

In the oldest-old group (90-95 years), the tone more closely resembled the older adults than the middle-aged adults. One 91-year old participant summarized: 
304: Oh, I'm not familiar with what [positive changes will happen to New Orleans], I don't know what they're going to do. ... [A] s far as I'm concerned it won't ever be New Orleans any more (91-year old male).

Several participants among the oldest-old expressed a hope, albeit a restrained and skeptical one, that a better New Orleans would emerge in the Katrina/Rita aftermath. The expressed vision of a "better" New Orleans varied, however. Some focused on religious and moral dimensions, like the two following participants:

323: I said I felt it was an opportunity to clean up the city of New Orleans, especially the negative moral reputation they have. They have an opportunity to take care of that (91-year old female).

312-R: New Orleans has been a wicked city. They're just going to have to get back in prayer. The churches down there [are] going to have to seek people and get back to praying because God will answer prayer when it comes from the heart and people are sincere. New Orleans can prosper and be a good city again. I believe 'til the day I die God allowed Satan to do that because of the wickedness that was down there...(92-year old female).

Other oldest-old participants focused on more concrete and structural elements of the city, including the levees, government, schools, and infrastructure, as follows:

314: And I don't know about the situation itself. Of course, I hope it will get rid of the bad part of New Orleans and maybe fix it up into something nice. I don't know if they can. Depends on the levees and what they can do (93-year old female).

308-R: I think New Orleans probably could be the only silver lining I can see in this whole thing. The part of the city that is going to come back will be better- better operated, and maybe not so much corruption, and [the] schools might be better (92-year old male).

A close review of potential "silver lining" notes from the oldest-old reveals that even when discussing potentially optimistic visions of the future, several thinly-veiled criticisms are evident. For 323, there is "an opportunity to clean up the city of New Orleans, especially the negative moral reputation they have." For 314, "New Orleans has been a wicked city" and "the churches down there [are] going to have to [get] people... back to praying." Participant 314 hopes the city will "get rid of the bad part" and 308-R thinks that "maybe" there will not be "so much corruption." Any one of these comments is not so much an authentic hope in a brighter future as it is an oblique if not direct cultural criticism. This brand of commentary and expression was less prevalent among the middle-aged group. We now move to a discussion of time of testing effects, where differences were evident in participants' responses across Waves 1 and 2 within 2 years of the storms.

\section{Time of Testing Effects}

In Study 1, data were collected 1 to 4-months after the storm and 6 to 14-months post-disaster to examine the temporal stability of participants' responses. In all, $89 \%$ of the participants in the immediate impact phase were retested during the post-disaster recovery phase, allowing us to evaluate the malleability of perceived silver linings over time. In Wave 1, participants stated concern for corruption at both the individual and bureaucratic level:

118: They [charity organizations] said they had never seen anything like that. They said they [some evacuees] were like animals (49-year old female).

206: People take advantage of things that are offered and they are really not entitled to them (76-year old male).

114: I don't have much faith in government (62-year old male).

302: That FEMA business was the biggest farce there ever was (93-year old female).

Interestingly, although $89 \%$ of participants in Wave 1 were retested in Wave 2, corruption concerns did not appear in Wave 2. Immediately after Katrina, disaster myths such as looting and guerilla warfare flooded the nation via media. Negative images of residents affected (mainly the poor and African-Americans) spread faster than the positive events happening. By Wave 2, however, participants may have had more first-hand exposure and not fallen victim to the "panicky public" fallacy (Tierney et al. 2006). Instead, a thankfulness to God coinciding with reports and discussions of others and themselves returning to religion were perceived as silver linings:

108-R: These are the times that you find the church houses full. [Tragedy] brings people not just closer together [physically] but it brings people closer to each other [emotionally] (47-year old male).

213-R: I would hope that some realize that there is a superior somebody in charge-humans are not in charge. We just don't have any say so over this, what happens like that, and I hope it has made some people realize [that]...[and] made them better people (78-year 
old female).

306-R: And I think it took a lot of people that remember ... brought them back to think how good the Lord was to them (91-year old female).

In summary, many of the participants thought the disasters of Katrina and Rita could have been minimized if individuals and larger agencies had learned their lesson and better prepared for the next storm that hit. In addition, many hoped for positive changes to New Orleans, such as stronger infrastructure, while witnessing positive change in their own community of Baton Rouge. However, it is important to note that older adults (65-89 years old) responded with negative perceived events without prompting, and that over time, the prevalence of mentioning of strangers helping strangers (so called "Good Samaritan" acts) increased. In a conceptual replication study, our goal was to compare and contrast emergent themes identified in Study 1 with themes obtained at least 5 years after Katrina in a new sample of adults who also lived in the greater metropolitan Baton Rouge area about 80 miles outside of the storm-devastated greater New Orleans region.

\section{Study 2}

\section{Participants and Procedure}

In Study 2, participants were an indirectly affected control group of non-coastal residents who were enrolled a postdisaster resilience study conducted 5 to 7 years after Hurricanes Katrina and Rita in the coastal parishes of south Louisiana (Cherry et al. 2015a, b). These control participants resided in the greater Baton Rouge metropolitan area, geographically comparable the catchment area in Study 1 ( $M$ age $=59.7$ years, $S D=12.3$ years, age range: 31 to 82 years). Age group and time of testing were not manipulated in this study. Control group membership was indicated by code to protect anonymity (1-30; see Cherry et al. 2015a for description). Completed open-end responses were available for 22 of the 30 non-coastal residents.

Informed consent was obtained for all based on the protocol approved by the LSU Institutional Review Board. Interviews were conducted in participants' homes or in a community location.

\section{Analyses and Coding}

Participants' responses to the same silver lining question as in Study 1 were analyzed using open and axial coding, two techniques from grounded theory methodology (Strauss and Corbin 1998). Weekly team-based analyses were employed with the same rigor as in Study 1 to enhance the reliability and validity of these findings. Three themes pertaining to potential silver linings emerged from their responses: (1) better preparedness/ learning experience, replicating Study 1; (2) strangers helping strangers; and a new theme, (3) improved family and social cohesion. These themes and supporting primary data are presented next.

\section{Theme 1 - Better Preparedness / Learning Experience}

Many of our participants in Study 1 had hoped that the two disasters would make the area better prepared for future disasters, but sufficient time had not passed for them to discern that judgment. At least 5 years after the Katrina and Rita disasters, people could now do so, as well as compare how they and other individuals, communities, and bureaucracies handled the more recent 2008 Hurricanes Gustav and Ike:

22: Well, I think, like me, people are conscientious about being better prepared (69-year old female).

26: I also think if you look at our government, they looked at things, and so now if we are... Well, obviously when we were hit again [in 2008], we responded better and were better prepared (44-year old female).

Although not as prevalent as in Study 1, some participants still felt the storm (Katrina) was not worth it, no matter what perceived benefits had arisen:

15: Well first, whatever they are, it wasn't worth it. Katrina and Rita were beyond...beyond acceptable catastrophes and ....all the silver linings in the world won't fix what was lost (59-year old male).

\section{Theme 2 - Strangers Helping Strangers}

Our second most salient theme in Study 2 was once again the perceived benefit of strangers helping strangers and other prosocial behaviors including goodwill. Participants mentioned help that they personally had received over the years from empathetic strangers, as well as witnessing people from across the country volunteering and working together to help victims:

16: Well, ...during [the Katrina/Rita] time I got telephone calls from South Carolina, Texas, Arizona, Kentucky, from friends all over the nation who wanted to do whatever they could to help us down here. They offered their homes, their dollars. They just...Everybody wanted to help. And I just thought that was amazing (65-year old female). 
9: I think one of the other things was that it showed the people in Louisiana how loving and kind we are because we reached out to everybody. Not just us, but everybody throughout the state. I mean, we were like one big happy family trying to help people (66-year old female).

10: Well, I think the positive outcomes were people pulling together, to help the people from New Orleans and the other cities. People showed that they have love for their fellow man. And, you know, it was all a common bond helping the Katrina and Rita victims (56-year old female).

\section{Theme 3 - Improved Family Relations and Social Cohesion}

As mentioned in the introduction, although all Study 1 and 2 participants were indirectly affected by the hurricanes, many had to assist family and friends who were going through complete loss and total devastation. Five years after the storms, these ties remained salient:

28: But, overall, I think it was, sad to say we had to have a hurricane but, for us, my family, and for my extended family, it was a benefit to us because of the changes that came as a result — positive changes, in our lives (75-year old male).

18: [My sabbatical] came as a positive from all those terrible things from Katrina. But, so, that was a fun thing we could do and we did other things more as a family that we couldn't have done before (51-year old female).

17: I know with, after...Katrina and Rita, it brought the family much closer and it seems as though we all had positive outlooks on helping each other and making sure everyone would get things they need if we can get them for them. [We also would] travel from Slidell to Mississippi helping my niece with all the devastation she had (69-year old female).

Overall, 5 years after the hurricanes many participants felt that the better preparedness of themselves, community benefits, and the state's improvements in preparation for future hurricanes were positive benefits of a tragic occurrence. As Louisiana is known for severe weather, having access to better resources for evacuation could assist local residents for years to come. Additionally, participants reported greater social cohesion, whether it be witnessing people unaffected by the storm volunteer their time, to improved relations with family and friends that they had hosted and supported during that time.

\section{General Discussion}

The primary aim of the present research was to examine perceived "silver linings" associated with the 2005 Hurricanes Katrina and Rita within the first 2 years (Study 1) and at least five years after the storms (Study 2). The inclusion of a longitudinal assessment (Study 1) and conceptual replication (Study 2) are strengths of the present research. Qualitative analyses of narrative data yielded three reliable and replicable themes across assessments and samples. These themes and their implications for disaster preparedness and current views on risk and resilience are discussed in turn next.

The first core theme pertained to Hurricanes Katrina and Rita as a learning experience with opportunities for improved disaster preparedness in future storms. This frequent and salient core theme emerged in the LHAS Wave 1 assessment, was replicated in Wave 2, and was also obtained in the conceptual replication 5 to 7 years later (Study 2). Given that south Louisiana is prone to seasonal hurricanes, the finding that disaster preparedness emerged as a prevalent and salient theme is not surprising. Further, this finding is suggestive of stress inoculation, meaning that repeated exposure to similar weather-related trauma may serve as a buffer, reducing the impact of future storms and facilitating adaptive coping strategies (Bonnano et al. 2010). On a related note, Ferraro (2003) found evidence for the inoculation hypothesis in older adults who survived the April 1997 flood in Grand Forks, ND, supporting prior research that post-disaster performance is influenced by pre-disaster performance (e.g., preparedness). Although a "better preparedness theme" is consistent with an inoculation perspective, it is important to realize that our participants were indirectly affected by the storms, living at least 80 miles away from the devastated coast of south Louisiana. Galea (2012) discussed at PopTech 2012 that the inoculation perspective of trauma, that people become accustomed to trauma the more number of times it occurs in one's lifetime, has not been supported by empirical science.

A second core theme that emerged in Study 1 (specifically during Wave 2 testing and replicated in Study 2) concerned the goodness of people, strangers helping strangers, and especially improved family and immediate social cohesion. Importantly, this theme is consistent with a large body of evidence from the research literature on resilience in early child development, where adaptive factors such as social support networks, strong family attachments, positive adaptive coping, and keeping perspective buffer against risk (Masten 2014; Southwick et al. 2014). High rankings of perceived social support have also been linked with a resilience trajectory in several multivariate studies after controlling for confounding demographic and predictor variables (Bonanno et al. 2007). After a disaster, survivors may feel a disconnect between received and perceived social support, especially after the disaster no longer captures the attention of the general 
population. Perceived social support, the subjective feeling of being supported, has only been moderately correlated with actual received social support (Norris and Kaniasty 1996). In that same study, however, an indirect path to reduced stress was found vis-à-vis received support, leading to greater feelings of perceived support and thus lowering stress levels. As our participants stated, people from all over the country both contacted and physically came to provide what they could for disaster relief (see also Cherry et al. 2010a, for related discussion). Not only is this perceived support and disaster relief assistance crucial for the redevelopment of the community, but individual community members feeling like they have support in a time of crisis is equally important. Hence, it is no surprise that at least 5 years after the storm, participants still cited improved social support as one of their main "silver linings."

Research on benefit-finding has increased tremendously in the past decade, with a PsycINFO database search yielding 273 articles from 1972 to 2005, while 2005-present presented 1257. Many of these studies are cross-sectional, making our longitudinal assessment (Study 1) and conceptual replication with a new sample of indirectly affected participants (Study 2) unique. Benefit-finding has been investigated in parents of children with disabilities, cancer patients, and HIV+ individuals with inconsistent results (Pakenham et al. 2004; Sears et al. 2003; Siegel and Schrimshaw 2006). On the other hand, Helgeson et al.'s (2006) meta-analysis of 87 cross-sectional studies conducted between 1985 and 2005 revealed that benefit finding was related to better mental health outcomes, but also related to more intrusive and avoidant thoughts about the stressor. Additionally, benefit finding was more strongly related to less depression and greater positive affect when the time since the traumatic event was more than 2 years, and was related to greater global distress only when the time since the traumatic event was 2 years or less. Helgeson et al.'s findings imply that perceiving benefits or silver linings after trauma may entail developmental processes and/or life course transitions, a potentially interesting direction for future research.

On a broader note, our findings have applied implications that warrant brief mention. Consistent with Affleck and Tennen (1996), participants may have relied on benefit finding to make sense of Hurricanes Katrina and Rita by searching for meaning from a "random" event. Identification of a silver lining, or meaning, may act as a form of emotion-focused coping (Tennen and Affleck 1999), an adaptational strategy intended to alleviate emotional distress. Adaptive coping has been linked to psychosocial well-being (Penley et al. 2002). Consequently benefit-finding cognitions may be associated with a post-disaster resilience trajectory, although further research is necessary. With respect to current therapy interventions, the finding that some participants viewed "returning to religion" and "thankfulness to God" as silver linings in Study
1 (Wave 2) is compatible with a small but growing literature on the psychotherapeutic role of spirituality in healing from trauma (see Harper and Pargament 2015, for review). Other evidence has shown that cognitive-behavioral therapy (CBT) sessions can increase benefit-finding in cancer patients (Antoni et al. 2001; Penedo et al. 2006). As CBT encourages the restructuring of harmful ways of thinking, patients may find it easier over time to focus on positives, such as appreciation of life, rather than on negatives. One must be careful, however, in extrapolating clinical findings to survivors of catastrophic disasters in the immediate aftermath of such events, as "quick fix" one-time crisis interventions may cause unintended harm (Walsh 2007).

The core themes presented here imply that benefit-finding, particularly identifying silver linings, may promote resilience after disaster by enhancing capacity to navigate destructive environmental events. Nonetheless, this central message should be tempered in light of at least three methodological limitations. First, participants in this study were living outside of the areas severely impacted by the 2005 Hurricanes Katrina and Rita. Individuals who have lost their homes and communities may have responded differently in the immediate aftermath of Hurricanes Katrina and Rita (but see Hatch et al. 2015 , for perceived silver linings at least 5 years after the 2005 storms). Second, the emergent themes are based on personal accounts of storm experiences, which are subject to possible biases and unintentional distortions (Cherry et al. 2015b). Third, a selection bias may limit the generalizability of these findings. People in poor health or living in marginal circumstances may not participate in a study on post-disaster recovery. Future research relating the frequency and nature of benefit finding to socioeconomic circumstances, among other individual difference variables, such as minority status and religiosity, is an important challenge that awaits future research.

Acknowledgments Jennifer Silva Brown is now at Drury University. Patricia F. Gendusa is now at Oshner Hospital. L. Joseph Su is now at the Food and Drug Administration. Study 1 was supported by grants from the Louisiana Board of Regents through the Millennium Trust Health Excellence Fund [HEF(2001-06)-02] and the National Institute on Aging P01 AG022064. Study 2 was supported by a grant from the Louisiana Board of Regents. This support is gratefully acknowledged. We also thank an anonymous reviewer for helpful comments on an earlier draft of this article.

Funding Study 1 was supported by grants from the Louisiana Board of Regents through the Millennium Trust Health Excellence Fund [HEF(2001-06)-02] and the National Institute on Aging P01 AG022064. Study 2 was supported by a grant from the Louisiana Board of Regents. This support is gratefully acknowledged. All procedures performed in studies involving human participants were in accordance with the ethical standards of the institutional and/or national research committee and with the 1964 Helsinki declaration and its later amendments or comparable ethical standards. 


\section{References}

Affleck, G., \& Tennen, H. (1996). Construing benefits from adversity: adaptational significance and dispositional underpinnings. Journal of Personality, 64, 899-922.

Anfara, V. A., Brown, K. M., Magione, T. L. (2002). Qualitative analysis on state: Making the research process more public. Educational Researcher, 28-38.

Antoni, M. H., Lehman, J. M., Kilbourn, K. M., Boyers, A. E., Culver, J. L., Alferi, S. M., \& Carver, C. S. (2001). Cognitive-behavioral stress management intervention decreases the prevalence of depression and enhances benefit finding among women under treatment for early-stage breast cancer. Health Psychology, 20(1), 20.

Barsky, L., Trainor, J., Torres, M. (2006). Disaster realities in the aftermath of Hurricane Katrina: Revisiting the looting myth. Natural Hazards Center Quick Response Report.

Bonanno, G. A., Galea, S., Bucciarelli, A., \& Vlahov, D. (2007). What predicts psychological resilience after disaster? The role of demographics, resources, and life stress. Journal of Consulting and Clinical Psychology, 75(5), 671-682. doi:10.1037/0022-006X.75. 5.671 .

Bonnano, G. A., Brewin, C. R., Kaniaty, K., \& La Greca, A. M. (2010). Weighing the costs of disaster: consequences, risks, and resilience in individuals, families, and communities. Psychological Science in the Public Interest, 11, 1-49.

Cherry, K. E. (Ed.). (2009). Lifespan perspectives on natural disasters: Coping with Katrina, Rita and other storms. New York: Springer.

Cherry, K. E., \& Galea, S. (2015). Resilience after trauma. In D. Ajdukovic, S. Kimhi, \& M. Lahad (Eds.), Resiliency: Enhancing coping with crisis and terrorism (NATO Science for Peace and Security Series, pp. 35-40). Netherlands: Ios Press.

Cherry, K. E., Galea, S., \& Silva, J. L. (2008). Successful aging and natural disasters: Role ofadaptation and resiliency in late life. In M. Hersen \& A. M. Gross (Eds.), Handbook of clinical psychology (Vol. 1, pp. 810-833). NJ: Wiley.

Cherry, K. E., Silva, J. L., \& Galea, S. (2009). Natural disasters and the oldest-old: A psychological perspective on coping and health in late life. In K. E. Cherry (Ed.), Lifespan perspectives on natural disasters: Coping with Katrina, Rita and other storms (pp. 171-193). New York: Springer.

Cherry, K. E., Allen, P. D., \& Galea, S. (2010a). Older adults and natural disasters: Lessons learned from Hurricanes Katrina and Rita. In P. Dass-Brailsford (Ed.), Crisis and disaster counseling: Lessons learned from Hurricane Katrina and other disasters (pp. 115130). Thousand Oaks: Sage.

Cherry, K. E., Galea, S., Su, L. J., Welsh, D. A., Jazwinski, S. M., Silva, J. L., \& Erwin, M. J. (2010b). Cognitive and psychosocial consequences of Hurricanes Katrina and Rita on middle aged, older, and oldest-old adults in the Louisiana Healthy Aging Study (LHAS). Journal of Applied Social Psychology, 40, 2463-2487.

Cherry, K. E., Silva Brown, J., Marks, L. D., Galea, S., Volaufova, J., Lefante, C., \& Jazwinski, S. M. (2011). Longitudinal assessment of cognitive and psychosocial functioning after Hurricanes Katrina and Rita: exploring disaster impact on middle-aged, older, and oldest-old adults. Journal of Applied Biobehavioral Research, 16, 187-211.

Cherry, K. E., Sampson, L., Nezat, P. F., Cacamo, A., Marks, L. D., \& Galea, S. (2015a). Long-term psychological outcomes in older adults after disaster: relationships to religiosity and social support. Aging \& Mental Health, 19(5), 430-443.

Cherry, K. E., Marks, L. D., Adamek, R., \& Lyon, B. A. (2015b). Younger and older coastal fishers face catastrophic loss after Hurricane Katrina. In K. E. Cherry (Ed.), Traumatic stress and long-term recovery: Coping with disasters and other negative life events. New York: Springer.
Ferraro, F. R. (2003). Psychological resilience in older adults following the 1997 flood. Clinical Geropsychologist, 26, 139-144.

Galea, S. (2012). Rebounding after trauma. [Recorded lecture]. Retrieved March 12, 2015, from http://poptech.org/popcasts/sandro_galea rebounding after trauma.

Gilbert, D. (2007). Stumbling on happiness. New York: Vintage.

Hatch, T. G., Cherry, K. E., Lu, Y., \& Marks, L. D. (2015). On seeing silver linings after the 2005 Hurricanes Katrina and Rita: Meaning making, positive adaption, and psychological growth. In K. E. Cherry (Ed.), Traumatic stress and long-term recovery: Coping with disasters and other negative life events. New York: Springer.

Harper, A. R., \& Pargament, K. I. (2015). Trauma, religion, and spirituality: Pathways to healing. In K. E. Cherry (Ed.), Traumatic stress and long-term recovery: Coping with disasters and other negative life events. New York: Springer.

Helgeson, V. S., Reynolds, K. A., \& Tomich, P. L. (2006). A metaanalytic review of benefit finding and growth. Journal of Consulting and Clinical Psychology, 74(5), 797-816.

Henderson, T. L., Roberto, K. A., \& Kamo, Y. (2010). Older adults' responses to Hurricane Katrina: daily hassles and coping strategies. Journal of Applied Gerontology, 29, 48-69. doi:10.1177/ 0733464809334287.

Johnson, J., \& Galea, S. (2009). Disasters and population health. In K. E. Cherry (Ed.), Lifespan perspectives on natural disasters: Coping with Katrina, Rita and other storms (pp. 281-326). New York: Springer.

Kilmer, R. P., Gil-Rivas, V., Tedeschi, R. G., \& Calhoun, L. G. (2010). Meeting the needs of children, families, and communities post-disaster: Lessons learned from hurricane Katrina and its aftermath. Washington, D.C.: American Psychological Association.

Marks, L. D., Cherry, K. E., \& Silva, J. L. (2009). Faith, crisis, coping and meaning making after Katrina. In K. E. Cherry (Ed.), Lifespan perspectives on natural disasters: Coping with Katrina, Rita and other storms (pp. 195-215). New York: Springer.

Marks, L., Cherry, K., Hatch, T., \& Lu, Y. (2015). Faith-based communities after a disaster: Successes and failures in the wakes of Hurricanes Katrina and Rita. In K. Cherry (Ed.), Traumatic stress and long-term recovery: Coping with disasters and other negative life events. New York: Springer.

Masten, A. S. (2014). Ordinary magic: Resilience in development. New York: Guilford Press.

Masten, A. S., \& Narayan, A. J. (2012). Child development in the context of disaster, war, and terrorism: pathways of risk and resilience. Annual Review of Psychology, 63, 227-257.

Neria, Y., Galea, S., \& Norris, F. H. (Eds.). (2009). Mental health and disasters. New York: Cambridge University Press.

Norris, F. H., \& Kaniasty, K. (1996). Received and perceived social support in times of stress: a test of the social support deterioration deterrence model. Journal of Personality and Social Psychology, 71(3), 498-511. doi:10.1037/0022-3514.71.3.498.

Norris, F. H., Friedman, M. J., Watson, P. J., Byrne, C. M., Diaz, E., \& Kaniasty, K. (2002). 60,000 disaster victims speak: part I. An empirical review of the empirical literature, 1981-2001. Psychiatry, 65(3), 207-239.

Osofsky, J. D., Osofsky, H. J., \& Harris, W. W. (2007). Katrina's children: social policy considerations for children in disasters. Social Policy Report, 21, 3-18.

Pakenham, K. I., Sofronoff, K., \& Samios, C. (2004). Finding meaning in parenting a child with Asperger syndrome: correlates of sense making and benefit finding. Research in Developmental Disabilities, 25(3), 245-264. doi:10.1016/j.ridd.2003.06.003.

Patton, M. Q. (2002). Qualitative research \& evaluation methods (3rd ed.). Thousand Oaks: Sage.

Penedo, F. J., Molton, I., Dahn, J. R., Shen, B. J., Kinsinger, D., Traeger, L., \& Antoni, M. (2006). A randomized clinical trial of group-based cognitive-behavioral stress management in localized prostate 
cancer: development of stress management skills improves quality of life and benefit finding. Annals of Behavioral Medicine, 31(3), 261-270.

Penley, J. A., Tomaka, J., \& Wiebe, J. S. (2002). The association of coping to physical and psychological health outcomes. A metaanalytic review. Journal of Behavioral Medicine, 25, 551-603.

Prati, G., \& Pietrantoni, L. (2009). Optimism, social support, and coping strategies as factors contributing to posttraumatic growth: a metaanalysis. Journal of Loss and Trauma, 14(5), 364-388.

Roberto, K. A., Kamo, Y., \& Henderson, T. (2009). Encounters with Katrina: Dynamics of older adults' social support networks. In K. E. Cherry (Ed.), Lifespan perspectives on natural disasters: Coping with Katrina, Rita and other storms (pp. 133-152). New York: Springer.

Ryff, C., Friedman, E., Fuller-Rowell, T., Love, G., Miyamoto, Y., Morozink, J., Radler, B., \& Tsenkova, V. (2012). Varieties of resilience in MIDUS. Social and Personality Compass, 6(11), 792-806.

Sears, S. R., Stanton, A. L., \& Danoff-Burg, S. (2003). The yellow brick road and the emerald city: benefit finding, positive reappraisal coping and posttraumatic growth in women with early-stage breast cancer. Health Psychology, 22(5), 487-497. doi:10.1037/0278-6133. 22.5.487.

Siegel, K., \& Schrimshaw, E. W. (2006). The stress moderating role of benefit finding on psychological distress and well-being among women living with HIV/AIDS. AIDS and Behavior, 11(3), 421433. doi:10.1007/s10461-006-9186-3.

Silva Brown, J., Cherry, K. E., Marks, L. D., Jackson, E. M., Volaufova, J., Lefante, C., \& Jazwinski, S. J. (2010). After hurricanes Katrina and Rita: gender differences in health and religiosity in middle-aged and older adults. Health Care for Women International, 31, 9971012.

Silva, J. L., Marks, L. D., \& Cherry, K. E. (2009). The psychology behind helping and prosocial behaviors: An examination from intention to action. In K. E. Cherry (Ed.), Lifespan perspectives on natural disasters: Coping with Katrina, Rita and other storms (pp. 119-240). New York: Springer.

Solomon, S. D., Smith, E. M., Robins, L. N., \& Fischbach, R. L. (1987). Social involvement as a mediator of disaster-induced stress. Journal of Applied Social Psychology, 17, 1092-1112.

Southwick, S. M., Bonanno, G. A., Masten, A. S., Panter-Brick, C., \& Yehuda, R. (2014). Resilience definitions theory, and challenges: interdisciplinary perspectives. European Journal of Psychotraumatology, 5, 25338. doi:10.3402/ejpt.v5.25338.

Strauss, A., \& Corbin, J. (1998). Basics of qualitative research: Techniques and procedures for developing grounded theory. Thousand Oaks: Sage.

EM-DAT (2015). Summarized Table of Natural Disasters in United States from 2006 to 2015. Retrieved January 23, 2015, from http://www. emdat.be/result-country-profile?disgroup $=$ natural\&country= usa\&period=2006\$2015\#summtable.

Tausch, C., Marks, L. D., Silva Brown, J. L., Cherry, K. E., Frias, T., MacWilliams, Z., \& Sasser, D. (2011). Religion and coping with trauma: qualitative examples from hurricanes Katrina and Rita. Journal of Religion Spirituality and Aging, 23, 236-253.

Tennen, H., \& Affleck, G. (1999). Finding benefits in adversity. In C. R. Synder (Ed.), Coping: The psychology of what works (pp. 297-304). New York: Oxford University Press.

Thompson, M. P., Norris, F. H., \& Hanacek, B. (1993). Age differences in the psychological consequences of Hurricane Hugo. Psychology and Aging, 8(4), 606.

Tierney, K., Bevc, C., \& Kuligowski, E. (2006). Metaphors matter: disaster myths, media frames, and their consequences in Hurricane Katrina. The Annals of the American Academy of Political and Social Science, 604(1), 57-81.

United States Census Bureau. (2012). Retrieved January 23, 2015, from https://www.census.gov/newsroom/releases/archives/facts_for features_special_editions/cb12-ff07.html.

Walsh, F. (2007). Traumatic loss and major disasters: strengthening faculty and community resilience. Family Process, 46, 207-227.

Weems, C. F., \& Banks, D. M. (2015). Severe stress and anxiety disorders in adolescence: The long-term effects of disasters. In K. E. Cherry (Ed.), Traumatic stress and long-term recovery: Coping with disasters and other negative life events. New York: Springer.

Weisler, R. H., Barbee, J. G., \& Townsend, M. H. (2006). Mental health and recovery in the gulf coast after hurricanes Katrina and Rita. The Journal of the American Medical Association, 296, 585-588.

Wright, M. O., Masten, A. S., \& Narayan, A. J. (2013). Resilience processes in development: Four waves of research on positive adaptation in the context of adversity. In S. Goldstein \& R. B. Brooks (Eds.), Handbook of Resilience in Children (2nd ed., pp. 15-37). New York: Springer. doi:10.1007/978-1-4614-3661- 42. 